International Journal of Mathematical, Engineering and Management Sciences

Vol. 1, No. 3, 107-121, 2016

https://dx.doi.org/10.33889/IJMEMS.2016.1.3-012

\title{
Additive Manufacturing and Big Data
}

\author{
Lidong Wang ${ }^{1 *}$, Cheryl Ann Alexander ${ }^{2}$ \\ ${ }^{1}$ Department of Engineering Technology, Mississippi Valley State University, USA \\ ${ }^{2}$ Technology and Healthcare Solutions, Inc., USA \\ *Corresponding author: 1wang22@students.tntech.edu
}

(Received June 20, 2016; Accepted July 8, 2016)

\begin{abstract}
Additive manufacturing (AM) can produce parts with complex geometric shapes and reduce material use and weight. However, there are limited materials available for AM processes; the speed of production is slower compared with traditional manufacturing processes. Big Data analytics helps analyze AM processes and facilitate AM in impacting supply chains. This paper introduces advantages, applications, and technology progress of AM. Cybersecurity in AM and barriers to broad adoption of AM are discussed. Big data in AM and Big Data analytics for AM are also presented.
\end{abstract}

Keywords: Big data, additive manufacturing, 3D printing, rapid prototyping, cybersecurity, high performance computation

\section{Introduction}

The process of linking items together in order to create 3D simulated data, usually layered, known as additive manufacturing (AM), differs from subtractive manufacturing methodologies (Campbell and Ivanova, 2013). AM, a type of direct manufacturing, progressed from rapid prototyping technology during the 1990's. Although the aim of rapid prototyping is to create non-functional or semi-functional representations directly from 3D computer models, the objective of direct manufacturing is to create wholly functional elements directly from 3D computer models. Therefore, rapid prototyping approaches such as stereolithography (SLA), selective laser sintering (SLS), and fused deposition modelling (FDM) advanced into several freeform fabrication technologies for direct manufacturing (Kobryn et al., 2006). Current data file format of AM is STL (Standard Tessellation Language or STereoLithography); future data file formats are additive manufacturing format (AMF) and 3D manufacturing format (3MF) (Chan, 2015).

The ASTM-approved AM method terminologies are itemized in the following:

(i) material extrusion-an AM process through which objects are selectively distributed through a nozzle or opening,

(ii) material jetting-an AM process through which droplets of build material are selectively placed,

(iii) binder jetting-an AM procedure through which a liquid bonding agent is selectively deposited in order to combine powder materials,

(iv) sheet lamination-an AM process through which pieces of material are bonded to create an article,

(v) powder bed fusion-an AM process in which thermal energy selectively bonds areas of a powder bed,

(vi) directed energy deposition-an AM process in which focused thermal energy is applied to unite ingredients by melting as the material is being deposited, and 
International Journal of Mathematical, Engineering and Management Sciences

Vol. 1, No. 3, 107-121, 2016

https://dx.doi.org/10.33889/IJMEMS.2016.1.3-012

vat photopolymerization-an AM process by which liquid photopolymer in a tank is selectively cured by light-activated polymerization (Wohlers, 2012). In a lot of situations, additive manufacturing and $3 \mathrm{D}$ printing are regarded as the same thing.

The aerospace and automotive industries at this time are using AM to build design models and anticipate soon to release non-critical and critical parts such as engine parts and complete aircraft wings (Brown et al., 2013). The materials in AM can be classified into plastics, metals, ceramics, composites, and biological substances (Huang and Leu, 2014). Plastics, metals, and ceramics are the most common materials for AM (Stahl, 2013). For the majority of AM processes, there is a standard generic sequence that is shown in Table 1 (Hopkinson, 2012).

\begin{tabular}{|l|l|}
\hline \multicolumn{1}{|c|}{ AM steps } & \multicolumn{1}{c|}{ Description } \\
\hline $\begin{array}{l}\text { Convert CAD model to } \\
\text { STL format }\end{array}$ & CAD model is converted into STL format representing the surface of a part using many triangles. \\
\hline Orient part (s) & $\begin{array}{l}\text { Operator uses experience to choose greatest orientation for example to minimize build time or to obtain } \\
\text { tolerances on key dimensions. }\end{array}$ \\
\hline $\begin{array}{l}\text { Generate supports if } \\
\text { required }\end{array}$ & $\begin{array}{l}\text { Software automatically offers supports where needed; however, experienced operators can usually edit } \\
\text { these so as to minimize need for manual support removal during post-processing. }\end{array}$ \\
\hline Create slice files & Software generates 2D profile description for each layer of the part plus supports to be made. \\
\hline $\begin{array}{l}\text { Fabricate part plus } \\
\text { supports }\end{array}$ & 2D profiles are sent to the machine to drive part creation. \\
\hline Post-process & $\begin{array}{l}\text { When parts are fabricated they need to be cleaned, for example to remove excess unfused powder or to } \\
\text { remove support structures. }\end{array}$ \\
\hline
\end{tabular}

Table 1. Generic process sequence for AM technologies

Stereolithography, laser sintering, fused deposition, direct metal laser sintering, 3D printing, layer object manufacturing, and ballistic particle manufacturing are AM processes. A comparatively quick method is $3 \mathrm{D}$ printing in contrast to other $\mathrm{AM}$ processes with low material prices. The process is like the laser sintering process although the powder is bonded with liquid adhesive instead of a laser. The powder is bonded together with liquid adhesive that is deposited on a layer of powder material. In order to give power and conquer fragility, a hardener is sometimes added to the part once complete. One method which forms models by firing micro-droplets of liquefied wax from a moving nozzle onto a build platform is ballistic particle manufacturing. The platform lowers to permit the wax to be affixed in repeated layers. Material costs for this process are low but the parts lack strength (Brown et al., 2013).

3D printers are categorized into liquid-based, solid-based, and powder-based. CAD drawings are translated into STL files in readiness for the printer. STL files are a mesh of polygons representative of the 3D CAD models. Slicing of the STL file produces each individual layer that consists of a cross section of the part. 3D printers clarify the STL files into portions. Parts are cleaned by eliminating extra material and support structures (Sealy, 2012). Rapid prototyping of 3D models is done by 3D printing and is initially created by a computer aided design (CAD) program, e.g., AutoDesk, AutoCAD, SolidWorks, or Creo Parametric. The original design is completed using a CAD program; it is then converted to an STL file. For each surface of the 3D model, information is stored by the STL file in triangulated sections. The data is sent to the printer for fabrication (Gross et al., 2014). 
International Journal of Mathematical, Engineering and Management Sciences

Vol. 1, No. 3, 107-121, 2016

https://dx.doi.org/10.33889/IJMEMS.2016.1.3-012

The paper is arranged as follows: the next section introduces benefits and advantages of AM; Section 3 introduces applications of AM; Section 4 presents technology progress of AM; Section 5 discusses challenges of AM; Section 6 presents big data in additive manufacturing; and the final section is conclusions.

\section{Benefits and Advantages of Additive Manufacturing}

AM offers special value to industry: complex geometries, assembly reduction, low-volume production, and custom geometries (Campbell and Ivanova, 2013). A lot of divisions of manufacturing could be revolutionized by AM and decreasing component lead time, material waste, energy usage, and carbon footprint (Herderick, 2011). Details about benefits of AM are as follows:

\section{(i) Design flexibility}

AM provides freedom to realize complex geometric shapes without additional cost (Gao et al., 2015). It can construct virtually any shape with intricate cellular structures, optimized material distribution, and integration (Sealy, 2012). Not only can AM produce net-shape articles for use as final products, but it can also manipulate the internal shape of articles in ways no other manufacturing process can obtain (Campbell and Ivanova, 2013).

\section{(ii) Part consolidation, assemblage and weight reduction}

AM processes permit the manufacture of geometric shapes that would otherwise necessitate construction of multiple parts if produced conventionally (Gao et al., 2015). Boeing is using laser sintered parts in the commercial jet Boeing 787. Elements for air ducts that would otherwise be an assembly of up to 15 parts are reduced to one complex part. Allowing a further optimized design to reduce weight, AM can have the freedom of geometry (Fawcett and Waller, 2014). This could potentially lead to a decrease of necessary raw materials used to make an in-service component for the aerospace industry (Herderick, 2011).

\section{(iii) Functional customization and complexity}

With AM, there is the efficient and design of personalized products. Therefore, the use of AM could determine design and efficient manufacture of personalized products from mass production to mass customization (Campbell and Ivanova, 2013). There is a huge market for custom products in the health care sector. Joint implants, dental crowns and bridges, and the production of custom perfectfit hearing aids can be produced by AM (Fawcett and Waller, 2014). As for functional complexity, the integration of these components; embedded hardware, sensors, actuators, conductive materials; and manufacture functional devices can be fulfilled by AM (Sealy, 2012).

\section{(iv) Material and property tailoring}

Materials can be processed by points or layers (Sealy, 2012). People will make materials within materials, embed and weave numerous substances into intricate designs, and co-fabricate entangled components using multi-material additive manufacturing technologies (Campbell and Ivanova, 2013).

(v) New product development

AM significantly reduces design iterations (Khanna et al., 2015). The use of AM has made a very significant debut in quickening the prototyping process. Ford has decreased product prototyping cycles from three months to as few days as a week using 3D printing (Fawcett and Waller, 2014). 
International Journal of Mathematical, Engineering and Management Sciences

Vol. 1, No. 3, 107-121, 2016

https://dx.doi.org/10.33889/IJMEMS.2016.1.3-012

(vi) Reducing inventories, reducing transport costs and reconfiguring supply chains

Printing in 3D permits producers and retailers to work with a smaller amount of stock instead stockpiling greater numbers of goods and attempting to foresee sales. By removing the requirement for intermediate and finished merchandise, 3D printing can also decrease transportation expenses by eliminating the need for intermediate and finished products to be shipped from one factory to another (Stahl, 2013). AM can make the manufacturing supply chain simpler and shorter. Perhaps companies manufacture parts on site or near consumers, if so, they will not need simpler and shorter the manufacturing supply chain. If companies manufacture parts on site or near to consumers, they do not need transport; therefore, it will eradicate needless international shipping (Royal, 2013). Companies can reduce inventory levels with the use of 3D printing by manufacturing on demand; this will save on inventory fees. Companies can also cut the total links within the supply chain through a combination of numerous processes and decreasing the total of parts in a product (Khanna et al., 2015). 3D printing has impacts on supply chains and the global logistics industry, which includes consequences for inventory and logistics, its influence in mass customization and portable manufacturing, the significance for digital supply chains and other supply chain trends such as cloud manufacturing (Mohr and Khan, 2015).

Table 2 (Grynol, 2014) outlines some main benefits of 3D printing; Table 3 (Fielding, 2012) lists potential AM implications for DOD.

\begin{tabular}{|l|l|}
\hline Rapid prototyping & $\begin{array}{l}\text { Solo objects can be formed reasonably without sustaining the mold and tooling costs of traditional } \\
\text { manufacturing. }\end{array}$ \\
\hline Rapid innovation & New revolutions can be formed and revised rapidly because 3D printing is an iterative process. \\
\hline Reduced overhead & $\begin{array}{l}\text { Operating costs necessary to capitalize in inventory and warehouse is decreased because objects can be } \\
\text { printed as required. }\end{array}$ \\
\hline Mass customization & Products can be modified for a single reason or formed in small and economical production runs. \\
\hline Mass production & $\begin{array}{l}\text { Exceptional products that cannot be made by means of traditional manufacturing procedures can be } \\
\text { produced for mass production. }\end{array}$ \\
\hline $\begin{array}{l}\text { Use of unique } \\
\text { materials }\end{array}$ & Materials, such as human tissue, can be produced by 3D printers. \\
\hline
\end{tabular}

Table 2. Benefits of 3D printing

\begin{tabular}{|l|l|}
\hline \multicolumn{1}{|c|}{ Aspects } & \multicolumn{1}{c|}{ Implications } \\
\hline Efficient use of resources & Less handling phases, net-shape, less assemblage, post-processing, less waste material, less energy \\
\hline Small lot productions & Production in lot size of 1, mass customization \\
\hline Rapid manufacturing & Tool-less, extreme cycle time decrease \\
\hline Agile manufacturing & Spare parts on demand, no stockpiles, simplified supply chain/logistics \\
\hline Reverse engineering & Scan and produce parts for legacy systems \\
\hline Lightweight structures & Weight removal rises with mission capabilities \\
\hline Modularity & New designs to switch elements in and out \\
\hline Complexity & Exotic structures, functionally-graded materials, fabricated moving joints, embedded electronics \\
\hline Shortening of supply chain & Possible usage of local raw materials \\
\hline
\end{tabular}

Table 3. Potential AM implications for DOD 
International Journal of Mathematical, Engineering and Management Sciences

Vol. 1, No. 3, 107-121, 2016

https://dx.doi.org/10.33889/IJMEMS.2016.1.3-012

\section{Applications of Additive Manufacturing}

(i) Aerospace

AM procedures like laser sintering are used to make some components of satellites. The most common laser engineering application, the net shaping (LENS) technique for direct part manufacturing, is useful for Aerospace (Aliakbari, 2012). Revolutions in lightweight structures that could see use in unmanned aerial vehicles (UAVs) could be made using AM (Herderick, 2011). Low aerospace volumes make 3D printing an appealing, lower-cost substitute to exchange established CNC machining and other tooling methods for smaller-scale parts and finished assemblies. There are a few leading aerospace manufacturers who are currently operating with 3D printing to fabricate jigs and fixtures. Some leading aerospace manufacturers are already using 3D printing to fabricate jigs and fixtures, production tooling, and finished parts for lightweight wing assemblies in small aircraft and UAVs. The plan and engineering flexibility gives rise to a more efficient aircraft. Containing fewer printed parts, the 3D printed parts are composed of less material to reduce their weight to roughly one-third or less that of the metal parts they exchange (Hiemenz, 2014). Aircraft components: Since 2002, the Boeing Airline Company has used selective laser sintering (SLS) for flight hardware in both military and commercial programs (Lyons, 2014). In spite of existing restrictions, predominantly with materials and structural integrity, aerospace corporations are discovering 3D printing for manufacturing countless parts of their goods. Boeing has employed the technology to create interior fragments of airplanes; meanwhile NASA has utilized it to create rocket engines and parts for satellites. Research is conducted to develop complex parts, such as satellites parts or components of NASA's rovers, including flame-retardant vents and housings, camera mounts, and large pod doors (Munoz et al., 2013).

(ii) Manufacturing industry and automotive industry

Because they are being customized and in few numbers, jigs and fixtures, templates, gauges, drill guides are kinds of manufacturing tools which are generally costly. AM has gained a good attention in this. One example in the machinery industry is applying light weight substances through AM to create drag chain links for mining industry. A big market of AM for direct part manufacturing is tooling. Two types of AM approaches in tooling are the indirect approach-making dies and molds (master patterns), and the direct approach- directly making inserts and dies (Aliakbari, 2012).

AM in Automobile components: Some engine parts for use in sports race cars have been made using direct metal laser sintering. Bentley and Rolls-Royce, luxury car producers, can create parts more cheaply using AM. Tesla, the manufacturer of electric cars, also fabricates automobile parts via 3D printers (Crocoll and Brühl, 2013). Using AM, most assemblies make audio/video, headrest, or engine control units (Aliakbari, 2012).

\section{(iii) Medical industry}

AM is leading to a revolution in the health care field, heading toward customized medicine where dental implants, orthopedics, and hearing aids are manufactured to fit an individual's distinctive physiology (Herderick, 2011). In medical aids, orthoses, splints, and prostheses, AM can be used for anatomic personalization of a device to enhance healing from trauma, anomaly, or defect. AM can improve the efficacy of a medical or surgical technique by creating tools and hardware for medical functions (Tuomi et al., 2014). A five-category classification for medical applications of AM includes

(a) models for preoperative development, instruction, and teaching;

(b) medical aids, supportive guides, splints, and prostheses; 
International Journal of Mathematical, Engineering and Management Sciences

Vol. 1, No. 3, 107-121, 2016

https://dx.doi.org/10.33889/IJMEMS.2016.1.3-012

(c) tools, instruments, and parts for pieces of medical tools;

(d) inert implants; and

(e) biomanufacturing (tissue engineering + AM) of artificial tissue. Sterilized titanium and medical plastics are among the most implanted AM materials (Huotilainen et al., 2013).

AM has been used in clinical practice. Medical imaging data sets can be the basis for geometry and there are some software tools available for reconstructing 3D models to create physical models for AM. AM implants are potentially used in surgical operations using medical imaging and 3D modeling. Inert implants can be produced by AM directly or indirectly. 3D modeling converts anatomical multi-slice data to 3D STL mesh format while making necessary adjustments like removing unnecessary tissue or imaging artifacts (Tuomi et al., 2014).

Emerging as a custom manufacturing choice for the health care devices industry, 3D printing is applicable to such devices as dental implants, hearing aids, prostheses, custom-made knee and hip implants, and surgical instruments (Khanna et al., 2015). Some dental laboratories use 3D printing. Oral scanning allows CAD software to produce AM crowns, bridges, stone models, and a range of orthodontic appliances (Stratasys, 2013). Using 3D printing in tissue engineering, the lower jaw of a patient was entirely replaced by an artificial jaw. The implant was printed using titanium powder. Parts of bones have been produced by $3 \mathrm{D}$ printing. 3D printers are currently producing numerous parts of the face and ears (Dambeck, 2013). The manufacture of intricate shapes and lightweight parts by 3D printing can be used to create implants. 3D printers making bone replacements and support structures for growing body parts are at various points of research. 3D printers can also be used to make models of human parts using computerized tomography (CT) scans or magnetic resonance imaging (MRI) images that assist surgeons while performing complicated surgeries. The exploration of new and specific surgical tools made by 3D printers is currently happening (Munoz et al., 2013).

\begin{tabular}{|c|c|}
\hline Industry sectors & Some emerging and near-term future uses \\
\hline $\begin{array}{l}\text { Automotive and industrial } \\
\text { manufacturing }\end{array}$ & $\begin{array}{l}\text { - } \quad \text { Combine numerous sections into a single complex part } \\
\text { - } \quad \text { Generate production tooling } \\
\text { - } \quad \text { Produce spare parts and components } \\
\text { - } \quad \text { Speed up the product progress cycle with rapid prototyping, form and fit testing }\end{array}$ \\
\hline Aerospace & $\begin{array}{l}\text { - Form complicated geometry parts not possible with traditional manufacturing } \\
\text { - Control density, stiffness, and other material properties of a part; also grade those } \\
\text { properties over a part } \\
\text { - } \quad \text { Create lighter parts }\end{array}$ \\
\hline Pharma/ Healthcare & $\begin{array}{l}\text { - Design surgery techniques using accurate anatomical models founded on CT scan or } \\
\text { MRI } \\
\text { - } \quad \text { Design custom orthopedic implants and prosthetics } \\
\text { - } \quad \text { Utilize 3-D printed cadavers for health education } \\
\text { - } \quad \text { Bioprint live tissues for testing during drug development }\end{array}$ \\
\hline Retail & $\begin{array}{l}\text { - Make designer toys, jewelry, games, and home decorations, etc. } \\
\text { - } \quad \text { Print spare or replacement parts for auto or home repair }\end{array}$ \\
\hline Sports & $\begin{array}{l}\text { - } \quad \text { Generate complicated geometry and shape not possible using traditional manufacturing } \\
\text { - } \quad \text { Produce custom protective gear for improved fit and safety } \\
\text { - } \quad \text { Create custom spike plates for soccer shoes grounded on biomechanical data } \\
\text { - } \quad \text { Produce multi-color and multi-material prototypes for merchandise analysis }\end{array}$ \\
\hline
\end{tabular}

Table 4. Developing uses of 3-D printing in different manufacturing sectors 
International Journal of Mathematical, Engineering and Management Sciences

Vol. 1, No. 3, 107-121, 2016

https://dx.doi.org/10.33889/IJMEMS.2016.1.3-012

(iv) Weapons

The world's initial handgun created almost completely with 3D printing was made and tested in 2013. It was made using 3D printing with ABS plastic; 15 of 16 pieces were created (Stahl, 2013).

The applications of 3D printing are becoming beyond rapid prototyping as 3D printers become faster, more simple to use, able to control several materials, and print active components or systems. The applications of 3-D printing are beyond rapid prototyping. Numerous corporate divisions are using 3-D printing and a few applications are listed in Table 4 (Earls and Baya, 2014). Some fields of application and the consequences of AM are shown in Table 5 (Zee et al., 2015).

\begin{tabular}{|l|l|l|}
\hline Sectors & \multicolumn{1}{|c|}{ Fields of application } & \multicolumn{1}{|c|}{ Consequences } \\
\hline Aerospace & $\begin{array}{l}\text { A small number of geometrically intricate and } \\
\text { lightweight components }\end{array}$ & $\begin{array}{l}\text { Less stocks } \\
\text { Decrease, possibly abolish tooling, welding, inventory, } \\
\text { and complete assembling lines }\end{array}$ \\
\hline Armament & $\begin{array}{l}\text { Geometry and processing soft and hard materials, } \\
\text { alteration and repair of parts }\end{array}$ & $\begin{array}{l}\text { Re-tooling becomes outdated, and reparation and re- } \\
\text { manufacturing turns out to be easier }\end{array}$ \\
\hline Automotive & $\begin{array}{l}\text { Functional prototypes, small and intricate parts for } \\
\text { luxury and antique parts }\end{array}$ & $\begin{array}{l}\text { Design and manufacturing tools become unessential } \\
\text { solid metallic objects, polymer based, three- } \\
\text { dimensional micro-electromechanical systems, } \\
\text { microwave circuits constructed on paper substrates, } \\
\text { grippers processes, hurrying of design process, functional } \\
\text { integration of a number of various electronic devices in a } \\
\text { plectrongle creation, functional prototypes, spare parts } \\
\text { single } \\
\text { produced on demand }\end{array}$ \\
\hline Dental & $\begin{array}{l}\text { Digital prostheses, dental aligners, invisible dental } \\
\text { braces, dental restoration }\end{array}$ & $\begin{array}{l}\text { Digitalizing the production process, high reproducibility } \\
\text { of production properties, less processing times }\end{array}$ \\
\hline
\end{tabular}

Table 5. Sections of function and the significances of additive manufacturing

\section{Technology Progress of Additive Manufacturing}

\subsection{Basic Types of 3D Printing and Typical Markets}

Most AM machines, using dimensional accuracy, have tolerance capabilities that are tighter within a few hundredths of a millimet (Gao et al., 2015). Through translation, the 3D printer converts the digitally supplied coordinates originating from the STL file into G-file via slicer software for 3D printing. The 3D STL file is divided into a sequence of two-dimensional (2D) horizontal cross sections (25-100 $\mu \mathrm{m}$, depending on the fabrication technique), allowing the three dimensional item to be printed. Laser scanning, CT, and MRI can generate data that can be changed to the STL format, which is helpful to the medical field. These digital scanning technologies can be combined with $3 \mathrm{D}$ printing. The capacity to modify a 3D printed scaffold for tissue regeneration enables personalized therapy. Drug delivery services have significantly utilized inkjet-based 3D printing (Gross et al., 2014). Fundamental kinds of 3D printing are itemized in Table 6 (Zee et al., 2015). 
International Journal of Mathematical, Engineering and Management Sciences

Vol. 1, No. 3, 107-121, 2016

https://dx.doi.org/10.33889/IJMEMS.2016.1.3-012

\begin{tabular}{|l|l|l|}
\hline \multicolumn{1}{|c|}{ Technology } & \multicolumn{1}{|c|}{ Materials } & \multicolumn{1}{c|}{ Typical markets } \\
\hline Material jetting - Droplets of build material are selectively deposited & Polymers, waxes & $\begin{array}{l}\text { Prototyping, } \\
\text { patterns }\end{array}$ \\
\hline $\begin{array}{l}\text { Binder jetting - Liquid bonding agent is selectively deposited for joining } \\
\text { powder material }\end{array}$ & $\begin{array}{l}\text { Metals, polymers, } \\
\text { foundry sand }\end{array}$ & $\begin{array}{l}\text { Prototyping, direct part, } \\
\text { casting molds }\end{array}$ \\
\hline $\begin{array}{l}\text { Material extrusion - Material are selectively dispensed through a nozzle or } \\
\text { orifice }\end{array}$ & Polymers & Prototyping \\
\hline $\begin{array}{l}\text { Powder bed fusion - Thermal energy selectively fuses regions of a powder } \\
\text { bed }\end{array}$ & Metals, polymers & Prototyping, direct part \\
\hline Sheet lamination - Sheets of material are bonded to form an item & Metals, paper & Prototyping, direct part \\
\hline $\begin{array}{l}\text { Directed energy deposition - Focused thermal energy is utilized to blend } \\
\text { materials by melting when the material is deposited }\end{array}$ & Metals & Direct part, repair \\
\hline $\begin{array}{l}\text { Vat photopolymerisation - Liquid photopolymer in a vat is selectively cured } \\
\text { by light-activated polymerisation }\end{array}$ & Photopolymers & Prototyping \\
\hline
\end{tabular}

Table 6. Essential categories of 3D printing

\subsection{Metal Methods of AM}

Several metal methods of AM are direct metal laser sintering (DMLS), selective laser melting (SLM), electron beam melting (EBM), EasyCLAD, laser consolidation (LC), LaserCusing, laser engineering, net shaping (LENS), and digital part materialization (ProMetal) (Aliakbari, 2012). Currently 3D printers can yield titanium and steel parts (McNulty et al., 2012). Alloys like stainless steel, titanium, cobalt chromium, etc. are presently processed for the growth and characterization of new AM materials. Nonetheless, numerous unique materials are being judged for further research. Countless efforts are in progress for the biomedical field to create new materials and/or advance material properties (metals and polymers) for biomedical therapies (Petrovic et al., 2012).

Powder bed, laser powder injection, and free form fabrication systems are three primary technology categories of direct metal fabrication that do not use lasers. Titanium alloys, nickel alloys, highgrade stainless steels, and countless others in the area of AM, are manufactured employing the use of lasers, electron beam, and arc techniques using an assortment of feedstocks.

Most of the microstructures created have too much "noise" which obstructs inspection depth with today's approaches, so new methodologies for nondestructive evaluation are essential. It is necessary to comprehend the material microstructure as a result of a particular thermal processing cycle. A complete material property database and testing methodology needs to be created (Herderick, 2011).

\subsection{AM of Functionally Graded Materials and Multi-Material Printing}

The thermal properties of functionally graded materials (FGM) and meso-structures, using macrosized elements, are controlled by AM. Effective cooling channels considerably improve the quality of thermal behavior in injection molding tools. It is impossible to create these complicated channels without using AM. One of the favorable potentials of AM consist of the complexity of geometry combined with methods for optimization (Doubrovski et al., 2011).

Laser deposition, direct metal deposition, 3D printing, and micro droplets dispensing are multiple production methods manipulated in developing heterogeneous items. The AM processes-multi-jet modeling, laser deposition manufacturing, and direct metal deposition-have been established in 
International Journal of Mathematical, Engineering and Management Sciences

Vol. 1, No. 3, 107-121, 2016

https://dx.doi.org/10.33889/IJMEMS.2016.1.3-012

fabricating heterogeneous pieces. Mask-image projection based stereolithography (MIP-SL) is also assuring for constructing heterogeneous things with digital materials. The input 3D model is initially divided into layers of two-dimensional (2D) mask images during the MIP-SL procedure. Next, the mask images produced are projected onto photosensitive resin which is cured and amassed to build a solid objects can be made using the multiple-material structure (Huang et al., 2013). Inkjet-like technology such as Voxeljet is the existing and future for multi-material printing (Earls and Baya, 2014).

\subsection{Modeling, Sensing and Control of AM}

For better control of the manufacturing cycle, closed loop feedback control sensing systems and intelligent feed forward schemes need to be established and combined into systems (Herderick, 2011). The uppermost importance in AM processes should be modeling, sensing, and control. It is essential to comprehend the transport phenomena of AM processes, it is crucial to model the temperature, stress, and composition history. It is difficult to predict the microstructures and fatigue properties resulting from AM processes. Supercomputing can greatly impact such modeling efforts. AM process sensing needs fast in-situ measurements of the temperature, cooling rate, and residual stress; the calibration of rapid optical sensors for high-accuracy dimensions; and in-process observation of geometric dimensions and the surface quality of completed layers. Imaging data can be obtained by using high-speed infrared thermography for microstructure prediction by measuring the resultant grain size from melt pool features. The distribution of a pool of manufacturing physical resources (such as AM machines), enabled by cloud manufacturing, is gaining notice. But, no speedily applicable cyber-physical systems for cloud-based AM exist. Future AM applications may include conformal, flexible electronics; products with embedded multi-material sensors and actuators; high-power, high-energy-density micro-batteries; cellular machines; turbine blades with internal cavities; lightweight, high-strength aerospace structures with material gradients; multifunctional houses; custom medications; and even human organs, etc. Fundamental research and advanced development is necessary to manage the in-situ diagnostics and governing of AM processes through the integration of modeling, sensing, and process control (Huang and Leu, 2014).

\subsection{Cybersecurity of AM}

AM's digital thread presents opportunities for cyber-attacks. Voids can be put into a component and internal layers properties can be changed without affecting the exterior layers. Note Fig. 1 shows a chance for cyber-attack in the AM process chain. The CAD model, the STL file, the toolpath file, and the physical machine itself are key stages in the process chain where an attack could happen. The most defenseless attack vector is the STL file. The detailed information is as follows (Sturm et al., 2014):

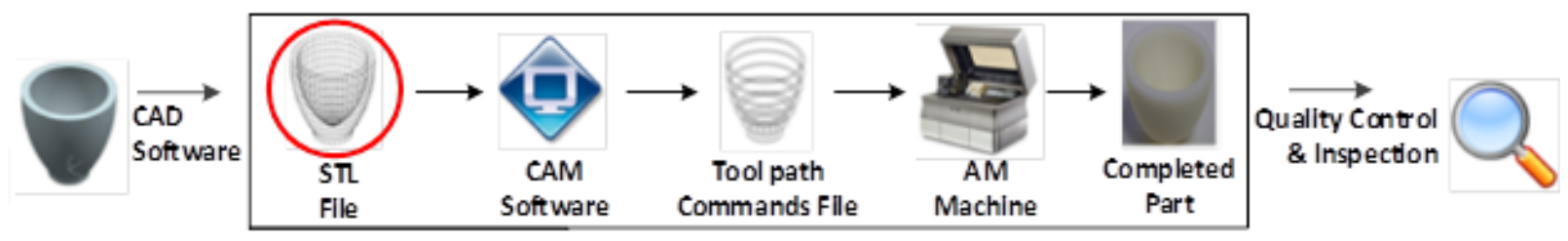

Fig. 1. Additive manufacturing procedure chain 
International Journal of Mathematical, Engineering and Management Sciences

Vol. 1, No. 3, 107-121, 2016

https://dx.doi.org/10.33889/IJMEMS.2016.1.3-012

(i) CAD Model: Attacks focus on stealing or corrupting files.

(ii) STL/AMF File: Simple file formats including both the STL and the AMF file (the current ISO/ASTM standard) with vertices of facets are vulnerable to the same types of attacks.

(iii) Toolpath File: Likely attacks on the toolpath are to put/eliminate material in the wrong location, to trigger layer placement either too close/far away from each other, and to damage the machine/part. When the file is sent from one computer to the machine, the toolpath file could be interrupted by a virus.

(iv) Physical Machine: This phase of the procedure can be exposed to Stuxnet type attacks, in which a worm modifies the firmware of the system's controller PC.

Recommendations were made as follows:

(i) improved software checks,

(ii) improved process monitoring, and

(iii) hashing/secure signing-allowing operators to check that the file they obtain is the same as the one that was transmitted (Sturm et al., 2014).

\subsection{AM Research Opportunities}

There is a growing body of knowledge in the field of design for AM (DfAM) (Doubrovski et al., 2011). Table 7 summarized some AM research opportunities (McNulty et al., 2012).

\begin{tabular}{|l|l|}
\hline Process control & Requirement for real time observation to adjust for errors to guarantee excellent output \\
\hline $\begin{array}{l}\text { Process modeling } \\
\text { and simulation }\end{array}$ & Need for additional basic science essential to AM \\
\hline $\begin{array}{l}\text { High-throughput } \\
\text { AM systems }\end{array}$ & A necessity to advance AM systems with greater printing speed and/or decreased process inadequacies \\
\hline $\begin{array}{l}\text { Part certification and } \\
\text { reliability }\end{array}$ & Prerequisite for component quality certification with industry-wide standards \\
\hline $\begin{array}{l}\text { Open architecture } \\
\text { AM systems }\end{array}$ & Requirement for systems that offer the freedom to experiment for evolving the basic understanding of AM \\
\hline $\begin{array}{l}\text { Printed electronics } \\
\text { and hybrid } \\
\text { AM systems }\end{array}$ & $\begin{array}{l}\text { Need to develop "printable" conductive materials and inks running with current AM processes; necessary } \\
\text { for development of hybrid AM systems with multi-material deposition capability to generate parts with }\end{array}$ \\
\hline $\begin{array}{l}\text { Anti-counterfeit } \\
\text { measures }\end{array}$ & Requirement for the development of anti-counterfeiting procedures for AM part construction \\
\hline Bio 3D printing & Necessary to improve bio-compatible materials and AM processes for medical device creation \\
\hline
\end{tabular}

Table 7. AM research opportunities

\section{Challenges of Additive Manufacturing}

Barriers to broad adoption of AM include:

(i) Problems with dimensional accuracy caused by the stair-stepping effect, difficulty in achieving tight manufacturing tolerances, and poor surface finish (Baumers, 2012; Huang and Leu, 2014; Khanna et al., 2015). Post-processing may become required and is contingent on the proposed use of a product. Post-processing is a manually intensive process and cannot be completed by the AM machine. This topic may possibly develop into an important topic in the case of a medium or high production volume (Stahl, 2013). 
International Journal of Mathematical, Engineering and Management Sciences

Vol. 1, No. 3, 107-121, 2016

https://dx.doi.org/10.33889/IJMEMS.2016.1.3-012

(ii) Limited in build volumes/part size, uncompetitive production cost at medium and large volumes, and diminished fabrication speed and process productivity. The 3D printing process is slower than conventional manufacturing processes (Baumers, 2012; Stahl, 2013; Khanna et al., 2015). AM does not use a closed loop system for instant feedback, contrary to conventional methods. So, AM is regarded as a process that is hard to regulate (Sealy, 2012).

(iii) Limited material suitability. The option for diverse raw materials as feedstock for 3D printers is still somewhat limited (Baumers, 2012; Stahl, 2013). There is lack of an exhaustive range of 3D printed materials that can mimic conventional materials. As for mechanical properties and bio-compatibility challenges, when using AM or 3D printing with medical devices, mechanical testing and bio-compatibility questions may arise (Khanna et al., 2015).

(iv) There is necessity for a need for an enhanced industrial infrastructure, including more robust supply chains of machines and materials (Gao, 2015). While 3D printing has the potential to decrease supply chain complexity by consolidating parts and inventory, testing and quality assurance processes can be a lot more complex. This increases downstream supply chain complexity. For product design, 3D printing can reduce supply chain leadtimes by producing prototypes quickly, which can speed up the entire development process. However, these can lead to other bottlenecks in the process, which can have a negative effect on lead-times (Mohr and Khan, 2015).

(v) AM is a complex procedure of deposition processes. Heat transfer, fluid mechanics, and continuum mechanics; melting, solidification, solid-state phase transformations, grain growth, and diffusion are a number of intricate and interacting physical phenomena. There is anisotropy in AM due to layering \& stitching and/or columnar grain structure (Kobryn et al., 2006). Depending on particular additive technology, processed material has better performance when the load is employed along the direction of the layer as compared to the build-up direction (Petrovic et al., 2012). AM technologies are suitable for products that feature individualized characteristics and have low-volume production. There is a tradeoff between the layer resolution and the overall scale of printed parts. AM products have anisotropic mechanical properties due to interlayer bonding deficiencies (Gao et al., 2015). AM technologies typically build up objects in planar and parallel layers, which causes the relatively weak bonding between layers (Doubrovski et al., 2011). It is needed to improve product quality, such as the need to advance the quality control of the AM process. AM endures a lack of a supportive framework, industry standards, and in-process qualification and certification methodologies (Royal, 2013; Huang and Leu, 2014; GAO, 2015).

(vi) CAD software and programs are considered inadequate for designing for AM. CAD is still designed for traditional manufacturing such as injection molding. Existing CAD systems are not strong for exploring the design freedoms of AM. Data management can help accelerate uptake of AM. However, there currently isn't enough computer memory to store the data required for producing a one-metre cubed functional part (Royal, 2013). An insufficiently skilled workforce, as well as existing design and analytical tools limit the use of AM (GAO, 2015).

Some main challenges of 3D printing are listed in Table 8 (Fielding, 2012). 
International Journal of Mathematical, Engineering and Management Sciences

Vol. 1, No. 3, 107-121, 2016

https://dx.doi.org/10.33889/IJMEMS.2016.1.3-012

\begin{tabular}{|l|l|}
\hline \multicolumn{1}{|c|}{ Aspects } & \multicolumn{1}{c|}{ Challenges } \\
\hline Rapid prototyping & $\begin{array}{l}\text { Entry-level 3D printers manufacture products that are often inferior to those produced using traditional } \\
\text { approaches. }\end{array}$ \\
\hline $\begin{array}{l}\text { Rapid } \\
\text { manufacturing }\end{array}$ & Depending on printer types, it can be slow to manufacture large volumes of products. \\
\hline Mass customization & Limited materials can be used through 3D printers. \\
\hline Mass production & While traditional manufacturing can produce large products, most 3D printers cannot. \\
\hline Economies of scale & Producing large volumes of some products can be very expensive using 3D printers. \\
\hline
\end{tabular}

Table 8. Challenges of 3D printing

\section{Big Data in Additive Manufacturing}

Big Data Analytics and additive manufacturing are two of nine fundamental technologies of Industry 4.0 (Rüßmann et al., 2015). Open invention and additive manufacturing is positioned for a more intense additional development, so that provisions such as mass customization and customer involvement can become increasingly more important, and in which commerce, but also services make use of big data, become open towards 'external' ideas and collaboration, and become more flexible (Zee et al., 2015). 3D printing, cloud computing/big data, and the Internet of Things (IoT) are three of 10 technologies most likely to transform the world during the next five years. The IoT is a technological evolution based on Internet-connected devices (BNP, 2015). One of trends of 3D printing supply chain management is digitalization of supply chains; big data technology will be a great enabler that facilitates 3D printing in impacting supply chains (Mohr and Khan, 2015).

Among the "four V's" of big data (volume, velocity, variety, and veracity), no one ranked them in importance with respect to materials science. Much discussion time was devoted to the last twovariety and veracity. There are many sources of uncertainty in materials data, with no consistent methods to verify data quality. Big data allow for correlations. Big data triage includes the following elements (Rapporteur, 2014):

- Detection: identify elements of interest.

- Classification: organize data automatically and in real time.

- Prioritization: use the information to inform adaptive data compression.

- Understanding: explain events for humans to understand and interpret the results.

Important data issues in materials science, such as proprietary data access and the lack of homogeneity, are data problems but not "big data" problems. It was suggested that the materials science community may be well served by using data reduction or extraction techniques so as to exit the big data regime- in other words, to make the "haystack" smaller and the search for the needle easier (Rapporteur, 2014).

AM presents a "Big Data" challenge: up to 2.3 Trillion Voxels in a typical build volume; 600 variables currently logged on a per seconds basis giving up to $300 \mathrm{MB}$ of data per build; up to 0.5 TB of data collected per build using in-situ monitoring. The informatics associated with the additive manufacturing process was explained. The sensors have been able to capture a large quantity of high-fidelity data; at this point, about $1 \mathrm{~TB}$ of sensor data are collected for each direct metal laser sintering (DMLS) build. Neural network and data mining/machine learning algorithms are used to 
International Journal of Mathematical, Engineering and Management Sciences

Vol. 1, No. 3, 107-121, 2016

https://dx.doi.org/10.33889/IJMEMS.2016.1.3-012

bound process variables. In-situ monitoring and Big Data analytics for additive manufacturing are important research topics (Rapporteur, 2014; Dehoff et al., 2015).

High performance computation (HPC) can be used in AM. Most of current research studies try to improve the modeling efficiency for a higher degree of complex geometry. HPC methods plus PC clusters, multiple core CPUs and GPUs have been utilized to quicken solid modeling, slicing and support generation. PC clusters, multiple core CPUs, and highly-parallel GPUs accelerate solid modeling including, Boolean and offsetting. GPU-based hardware acceleration has been used in sampling procedures. Further parallel offsetting procedures have been projected and completed on multiple core CPUs with signed distance field, triangular mesh representation, and GPUs with voxel representation (Gao et al., 2015).

\section{Conclusion}

AM enables complicated forms or constructions, individualizes products for users, and simplify manufacturing processes and supply chains. There is very little wasted material in AM; therefore, AM is cost-efficient. AM has potential in manufacturing complex and organic-shaped models. AM can use data from medical images and manufacture models for surgical simulation, training, and education.

Disadvantages of AM lie in part accuracy, surface finish, production speed, limited build size, limited materials and properties, necessity for criterion and accreditation, and nonexistence of AM standards, etc. AM are slower than injection molding and traditional manufacturing methods. Generally, AM components do not act identically in all directions. AM is facing a challenge in validation of mechanical properties of existing materials. It is needed for further process understanding of AM.

Big Data analytics helps to perform process analysis, monitoring, and decision making. Big Data analytics for AM and cybersecurity of AM are important research topics.

\section{Reference}

Aliakbari, M. (2012). Additive manufacturing: State-of-the-art, capabilities, and sample applications with cost analysis. Master of Science Thesis, Royal Institute of Technology.

Baumers, M. (2012). Economic aspects of additive manufacturing: benefits, costs and energy consumption (Doctoral dissertation, (C) Martin Baumers). Loughborough University, UK.

BNP (2015). Transforming the World through Technology. Technical Report, Ceramic Industry, August.

Brown, C., Lubell, J., \& Lipman, R. (2013). Additive manufacturing technical workshop summary report. NIST, Technical Note, (1823).

Campbell, T. A., \& Ivanova, O. S. (2013). Additive manufacturing as a disruptive technology: Implications of three-dimensional printing. Technology \& Innovation, 15(1), 67-79.

Chan, S. (2015). Achieving higher level data interoperability with 3D printing. Global Product Data Interoperability Summit, 1-30.

Crocoll, S., Brühl, J. (2013). 3-D-Drucker: Wie die Industrie gehackt wird, Süddeutsche Zeitung Digitale Medien GmbH/ Süddeutsche Zeitung GmbH. Munich, 2013. http://www.sueddeutsche.de/wirtschaft/-ddrucker-wie-dieindustrie-gehackt-wird-1.1583784 
International Journal of Mathematical, Engineering and Management Sciences

Vol. 1, No. 3, 107-121, 2016

https://dx.doi.org/10.33889/IJMEMS.2016.1.3-012

Dambeck, H. (2013). Knochenersatz: Frau erhält neuen Unterkiefer aus 3D-Drucker. Spiegel online. Hamburg: 2012. http://www.spiegel.de/wissenschaft/medizin/knochenersatz-frauerhaelt-neuenunterkiefer-aus-3d-drucker-a-813885.html.

Dehoff, R., et al. (2015). In-situ process monitoring and big data analysis for additive manufacturing of Ti6All-4V. Workshop Presentation, Oak Ridge National Lab, Oct 6, 1-21.

Doubrovski, Z., Verlinden, J. C., \& Geraedts, J. M. (2011, January). Optimal design for additive manufacturing: opportunities and challenges. In ASME 2011 International Design Engineering Technical Conferences and Computers and Information in Engineering Conference (pp. 635-646). American Society of Mechanical Engineers.

Earls, A. and Baya, V. (2014). The road ahead for 3-D printers. PwC Technology Forecast, 2, 2-11.

Fawcett, S. E., \& Waller, M. A. (2014). Supply chain game changers - mega, nano, and virtual trends - and forces that impede supply chain design (ie, building a winning team). Journal of Business Logistics, 35(3), 157-164.

Fielding, J. (2012). National Advanced Manufacturing Innovation Institute. Additive Manufacturing Symposium, Washington, DC, August 20, 2012.

GAO (2015). 3D Printing: Opportunities, challenges, and policy implications of additive manufacturing. GAO-15-505SP, Addictive Manufacturing Forum, June, 1-63.

Gao, W., Zhang, Y., Ramanujan, D., Ramani, K., Chen, Y., Williams, C. B., \& Zavattieri, P. D. (2015). The status, challenges, and future of additive manufacturing in engineering. Computer-Aided Design, 69, 6589.

Gross, B. C., Erkal, J. L., Lockwood, S. Y., Chen, C., \& Spence, D. M. (2014). Evaluation of 3D printing and its potential impact on biotechnology and the chemical sciences. Analytical Chemistry, 86(7), 32403253.

Grynol, B. (2014). Disruptive manufacturing: The effects of 3D printing. Publisher: Canadian Electronic Library.

Herderick, E. (2011). Additive manufacturing of metals: a review. Materials science and technology (MS\&T) 2011, October 16-20, Columbus, Ohio, USA, 1413-1425.

Hiemenz, J. (2014). Additive manufacturing trends in aerospace. White Paper, Stratasys, USA, 1-11.

Hopkinson, N. (2012). Additive Manufacturing: Technology and Applications. British Educational Communications and Technology Agency, Loughborough, UK.

Huang, P., Deng, D., \& Chen, Y. (2013, November). Modeling and fabrication of heterogeneous threedimensional objects based on additive manufacturing. In ASME 2013 International Mechanical Engineering Congress and Exposition (pp. V02AT02A056-V02AT02A056). American Society of Mechanical Engineers.

Huang, Y., \& Leu, M. C. (2014). Frontiers of Additive Manufacturing Research and Education. Report of NSF Additive Manufacturing Workshop, Center for Manufacturing Innovation, University of Florida, USA, March, 1-35.

Huotilainen, E., Paloheimo, M., Salmi, M., Paloheimo, K. S., Björkstrand, R., Tuomi, J., \& Mäkitie, A. (2013). Imaging requirements for medical applications of additive manufacturing. Acta Radiologica, 0284185113494198.

Khanna, A., Balaji, S., Jawahar, T., Daniel, A. (2015). 3D Printing: New Opportunities for the Medical Devices Industry. White Paper, Tata Consultancy Services (TCS), 1-13. 
International Journal of Mathematical, Engineering and Management Sciences

Vol. 1, No. 3, 107-121, 2016

https://dx.doi.org/10.33889/IJMEMS.2016.1.3-012

Kobryn, P. A., Ontko, N. R., Perkins, L. P., \& Tiley, J. S. (2006). Additive manufacturing of aerospace alloys for aircraft structures. Air Force Research Lab Wright-Patterson AFB OH Materials and Manufacturing Directorate.

Lyons, B. (2014). Additive manufacturing in aerospace: Examples and research outlook. The Bridge, 44(3).

McNulty, C. M., Arnas, N., \& Campbell, T. A. (2012). Toward the printed world: Additive manufacturing and implications for national security. Defense Horizons, (73), 1.

Mohr, S., \& Khan, O. (2015). 3D Printing and Supply Chains of the Future. Innovations and Strategies for Logistics and Supply Chains, 147-174.

Munoz, C., Kim, C., Armstrong, L. (2013). Layer-by-Layer: Opportunities in 3D printing Technology trends, growth drivers and the emergence of innovative applications in 3D printing. White Paper, MaRS, December, 1-37.

Petrovic, V., Blasco, J. R., Haro, J. V., \& Portolés, L. (2012). Additive manufacturing solutions for improved medical implants. INTECH Open Access Publisher.

Rapporteur, M. M. (2014). Big Data in Materials Research and Development: Summary of a Workshop. Defense Materials Manufacturing and Infrastructure Standing Committee, National Materials and Manufacturing Board, Division on Engineering and Physical Sciences, National Research Council, 179.

Royal Academy of Engineering (2013). Additive manufacturing: opportunities and constraints. A summary of a roundtable forum, 23 May, 1-21.

Rüßmann, M., Lorenz, M., Gerbert, P., Waldner, M., Justus, J., Engel, P., \& Harnisch, M. (2015). Industry 4.0: The Future of Productivity and Growth in Manufacturing Industries. Boston Consulting Group.

Sealy, W. (2012). Additive manufacturing as a disruptive technology: how to avoid the pitfall. American Journal of Engineering and Technology Research, 12(1), 86-93.

Stahl, H. (2013). 3D printing-risks and opportunities. Öko-Institut eV Institute for Applied Ecology, 3-4.

Stratasys (2013). Digital Dentistry 3D printing makes digital dentistry happen. http://www.stratasys.com/industries/dental

Sturm, L., Williams, C. B., Camelio, J. A., White, J., \& Parker, R. (2014). Cyber-physical vunerabilities in additive manufacturing systems. Context, 7,8 .

Tuomi, J., Paloheimo, K. S., Vehviläinen, J., Björkstrand, R., Salmi, M., Huotilainen, E., \& Mäkitie, A. A. (2014). A novel classification and online platform for planning and documentation of medical applications of additive manufacturing. Surgical Innovation, 21(6), 553-559.

Wohlers, T. (2012, June). Recent Trends in Additive Manufacturing. In Proceedings of 17th European Forum on Rapid Prototyping and Manufacturing, Paris, France.

Zee, F. van der, Rehfeld, D., Hamza, C. (2015). Open Innovation in Industry, Including 3D Printing. Directorate General for Internal Policies Policy Department A: Economic and Scientific Policy, European Parliament, September, 1-86. 